\title{
Inhibition of Hydrogen Sulfide-induced Angiogenesis and Inflammation in Vascular Endothelial Cells: Potential Mechanisms of Gastric Cancer Prevention by Korean Red Ginseng
}

\author{
Ki-Seok Choi ${ }^{1 \#}$, Heup Song ${ }^{2 \#}$, Eun-Hee Kim ${ }^{1}$, Jae Hyung Choi ${ }^{1}$, Hua Hong ${ }^{1}$, Young-Min Han ${ }^{1}$, and \\ Ki Baik Hahm ${ }^{1,2 *}$ \\ ${ }^{1}$ Lab of Translational Medicine, Lee Gil Ya Cancer and Diabetes Institute, Gachon Univeristy of Medicine and Science, \\ Incheon 406-840, Korea \\ ${ }^{2}$ Department of Gastroenterology, Gachon Univeristy Gil Hospital, Gachon Graduate School of Medicine, Incheon 405-760, \\ Korea
}

Previously, we reported that Helicobacter pylori-associated gastritis and gastric cancer are closely associated with increased levels of hydrogen sulfide $\left(\mathrm{H}_{2} \mathrm{~S}\right)$ and that Korean red ginseng significantly reduced the severity of $H$. pylori-associated gastric diseases by attenuating $\mathrm{H}_{2} \mathrm{~S}$ generation. Because the incubation of endothelial cells with $\mathrm{H}_{2} \mathrm{~S}$ has been known to enhance their angiogenic activities, we hypothesized that the amelioration of $\mathrm{H}_{2} \mathrm{~S}$-induced gastric inflammation or angiogenesis in human umbilical vascular endothelial cells (HUVECs) might explain the preventive effect of Korean red ginseng on $H$. pylori-associated carcinogenesis. The expression of inflammatory mediators, angiogenic growth factors, and angiogenic activities in the absence or presence of Korean red ginseng extracts (KRGE) were evaluated in HUVECs stimulated with the $\mathrm{H}_{2} \mathrm{~S}$ generator sodium hydrogen sulfide (NaHS). KRGE efficiently decreased the expression of cystathionine $\beta$-synthase and cystathionine $\gamma$-lyase, enzymes that are essential for $\mathrm{H}_{2} \mathrm{~S}$ synthesis. Concomitantly, a significant decrease in the expression of inflammatory mediators, including cyclooxygenase-2 and inducible nitric oxide synthase, and several angiogenic factors, including interleukin (IL)-8, hypoxia inducible factor-1a, vascular endothelial growth factor, IL-6, and matrix metalloproteinases, was observed; all of these factors are normally induced after NaHS. An in vitro angiogenesis assay demonstrated that NaHS significantly increased tube formation in endothelial cells, whereas KRGE pretreatment significantly attenuated tube formation. NaHS activated p38 and Akt, increasing the expression of angiogenic factors and the proliferation of HUVECs, whereas KRGE effectively abrogated this $\mathrm{H}_{2} \mathrm{~S}$-activated angiogenesis and the increase in inflammatory mediators in vascular endothelial cells. In conclusion, KRGE was able to mitigate $\mathrm{H}_{2} \mathrm{~S}$-induced angiogenesis, implying that antagonistic action against $\mathrm{H}_{2} \mathrm{~S}$-induced angiogenesis may be the mechanism underlying the gastric cancer preventive effects of KRGE in H. pylori infection.

Keywords: Panax ginseng, Hydrogen sulfide, Helicobacter pylori, Korean red ginseng, Angiogenesis, Cancer prevention

\section{INTRODUCTION}

Small molecular weight gases, including nitric oxide (NO), carbon monoxide (CO), and hydrogen sulfide

cc This is an Open Access article distributed under the terms of the Creative Commons Attribution Non-Commercial License (http://creativecommons.org/licenses/by-nc/3.0/) which permits unrestricted non-commercial use, distribution, and reproduction in any medium, provided the original work is properly cited.

(C) The Korean Society of Ginseng
$\left(\mathrm{H}_{2} \mathrm{~S}\right)$, constitute a unique class of biomaterials that are indispensable for maintaining the homeostasis of biologi-

Received 07 Sep. 2011, Revised 04 Mar. 2012, Accepted 04 Mar. 2012

${ }^{\#}$ These authors contributed equally to this work.

*Corresponding author

E-mail: hahmkb@gachon.ac.kr

Tel: +82-32-899-6055, Fax: +82-32-899-6054 
cal systems. These substances readily convey signals from one site to another in autocrine, paracrine or juxtacrine fashions based on their high membrane permeability [1-3]. However, the evidence that these gases have biologically significant functions beyond homeostasis is increasing, and they have been implicated in the pathogenesis of diverse clinical diseases. Because gases easily penetrate the cell barrier and diffuse more rapidly than other signaling molecules, their impact on disease pathogenesis seems to be far broader and more critical than their conventionally acknowledged roles imply. Furthermore, these gases could be promising therapeutic targets [4-6].

$\mathrm{H}_{2} \mathrm{~S}$, which, like $\mathrm{NO}$ and $\mathrm{CO}$, has biological functions, was first known as a "toxic gas", and it was recognized for decades only as an environmental pollutant and principal offender in halitosis based on its strong odor of rotten eggs. $\mathrm{H}_{2} \mathrm{~S}$ is endogenously synthesized in various mammalian tissues by cystathionine $\beta$-synthase (CBS) and cystathionine $\gamma$-lyase (CSE), two pyridoxal-5'phosphate-dependent enzymes that are responsible for metabolizing L-cysteine [7]. L-cysteine, the substrate of CBS and CSE, is a sulfur-containing amino acid that can be derived from gastrointestinal sources or liberated from endogenous proteins. Despite its historical notoriety, increasing evidence suggests that $\mathrm{H}_{2} \mathrm{~S}$ could have beneficial physiological roles, including in the regulation of vasodilatation, the modulation of inflammation, and the modulation of gut signaling. On the basis of these beneficial activities, $\mathrm{H}_{2} \mathrm{~S}$ has become a key target for new therapeutics; for instance, the $\mathrm{H}_{2} \mathrm{~S}$-non-steroidal antiinflammatory drug (NSAID) was developed as a gastrointestinal (GI)-safe NSAID for the amelioration of GI motility disorders [8-10].

However, in the context of Helicobacter pylori infection or $\mathrm{H}$. pylori-associated carcinogenesis, $\mathrm{H}_{2} \mathrm{~S}$ seems to a mediator of gastric inflammation and an essential promoter of gastric carcinogenesis. In the stomach, $\mathrm{H}_{2} \mathrm{~S}$ may up-regulate the inflammatory response via the stimulation of immune cells and reactive oxygen species from activated neutrophils, which convert $\mathrm{H}_{2} \mathrm{~S}$ to sulfite and thus may further up-regulate leukocyte adhesion and neutrophil functions [11]. In addition to its role in H. pylori infection, Li et al. [12] observed increased $\mathrm{H}_{2} \mathrm{~S}$ synthesis during lipopolysaccharide (LPS)-induced inflammation in mice. Conversely, the inhibition of $\mathrm{H}_{2} \mathrm{~S}$ synthesis by DL-propargylglycine, a CSE inhibitor, dramatically reduced the severity of LPS-induced inflammation in various organs. Zhang et al. [13] reported that endogenous $\mathrm{H}_{2} \mathrm{~S}$ could regulate leukocyte trafficking in a cecal ligation and puncture-induced sepsis model.
In addition to increased leukocyte-mediated inflammation, $\mathrm{H}_{2} \mathrm{~S}$ can induce endoplasmic reticulum stress and subsequent apoptosis and may interact with other gases to enhance inflammation and organ dysfunction $[14,15]$. Therefore, $\mathrm{H}_{2} \mathrm{~S}$ might be a "villain" in the GI tract. However, similar to the "double-edged sword" role of NO in inflammation and carcinogenesis, the significance of $\mathrm{H}_{2} \mathrm{~S}$ in angiogenesis may have both positive and negative effects. For example, $\mathrm{H}_{2} \mathrm{~S}$-induced angiogenesis is beneficial in wound healing, cardioprotection, and resolving NSAID-induced damage, but it can also promote cancer growth and metastasis.

Korean red ginseng has been reported to reduce the risk of cancer in diverse organs, including the lips, oral cavity, pharynx, larynx, esophagus, lung, liver, pancreas, ovary, colon, rectum, and stomach, and Panax ginseng has been classified as a non-organ-specific cancer preventive molecule [16]. Our previous in vitro and in vivo studies $[17,18]$ have shown the mitigating effects of Korean red ginseng on $H$. pylori-associated atrophic changes and gastric carcinogenesis, indicating that Korean red ginseng extract (KRGE) may be a good example of a natural treatment to protect against $H$. pylori-associated carcinogenesis. In this study, to test the hypothesis that KRGE might prevent gastric cancer by mitigating $\mathrm{H}_{2} \mathrm{~S}$ generation and its pro-angiogenic activity, we performed in vitro experiments to document the influence of $\mathrm{H}_{2} \mathrm{~S}$ on endothelial cell activation and the influence of KRGE on $\mathrm{H}_{2} \mathrm{~S}$-associated angiogenic activities.

\section{MATERIALS AND METHODS}

\section{Reagents}

KRGE was provided by the Korean Ginseng Corporation (Daejeon, Korea), which is the most concentrated and pure form of 100\% 6-year-old premium Korean red ginseng roots available on the market. KRGEs retain the rich flavor of ginseng and their active components at an optimal level, such that even a small dose is enough to reap all of the health benefits of red ginseng. Sodium hydrogen sulfide (NaHS) and 3-(4, 5-dimethylthiazol2-yl)-2,5-diphenyltetrazolium bromide (MTT) were purchased from Sigma Aldrich (St. Louis, MO, USA). Anti-phospho-Akt, anti-Akt, anti-phospho-p38, antiphospho-STAT3, and anti-phospho-JAK2 antibodies were purchased from Cell Signaling Technology (Danvers, MA, USA) and anti- $\beta$-actin, anti-phospho-ERK, and anti-p38 antibodies were purchased from Santa Cruz Biotechnology (Santa Cruz, CA, USA). The cyclooxygenase (COX)-2 antibody was purchased from Thermo 
Fisher Scientific (Fremont, CA, USA), and the HIF-1 antibody was purchased from BD Bioscience (San Jose, CA, USA).

\section{Cell culture}

Human umbilical vein endothelial cells (HUVECs) were purchased from InnoPharmaScreen (Asan, Korea). HUVECs and human endothelial cells were cultured in M199 medium (InnoPharmaScreen). The cells were maintained at $37^{\circ} \mathrm{C}$ in a humidified atmosphere containing $5 \% \mathrm{CO}_{2}$. Cultures containing $1.0 \times 10^{5} / \mathrm{mL}$ HUVECs were seeded in appropriate dishes and incubated for $24 \mathrm{~h}$, after which the media were exchanged for media containing Korean red ginseng $(0-100 \mu \mathrm{g} / \mathrm{mL})$, and the cells were incubated for a further $2 \mathrm{~h}$. The HUVECs were then treated with $100 \mu \mathrm{g} / \mathrm{mL} \mathrm{NaHS}$ for 0 to $24 \mathrm{~h}$.

\section{Measurement of cell viability}

HUVECs were plated at a density of $1.0 \times 10^{5}$ cells/ $\mathrm{ml}$ in 96-well plates, and the cell viability was determined by a conventional MTT reduction assay. After incubation with sodium hydrogen sulfide $(0,50,100$, 200 , and $300 \mu \mathrm{g} / \mathrm{mL}$ ), cells were treated with MTT solution (final concentration $1 \mathrm{mg} / \mathrm{mL}$ ) for $2 \mathrm{~h}$. The dark blue formazan crystals formed in intact cells were solubilized with DMSO, and absorbance was measured at $570 \mathrm{~nm}$ with a microplate reader (Molecular Devices, Silicon Valley, CA, USA).

\section{Western blot analysis}

Treated cells were washed twice with phosphatebuffered saline and then lysed in ice-cold cell lysis buffer (Cell Signaling Technology) containing $1 \mathrm{mM}$ phenylmethylsulfonyl fluoride (Sigma Aldrich). After $20 \mathrm{~min}$ of incubation, samples were centrifuged at $10,000 \times \mathrm{g}$ for $10 \mathrm{~min}$. The supernatants were then collected. The proteins in the lysates were separated by sodium dodecyl sulfate polyacrylamide gel electrophoresis and transferred to polyvinylidene fluoride membranes, which were then incubated with primary antibodies, washed, incubated with peroxidase-conjugated secondary antibodies, rewashed, and then visualized using an enhanced chemiluminescence system (GE Healthcare, Buckinghamshire, UK).

\section{RNA isolation and reverse transcription poly- merase chain reaction}

After incubation, the media was removed by suction, and the cells were washed twice with Dulbecco's phosphate-buffered saline. RiboEX (500 $\mu$ L; GeneAll, Seoul, Korea) was added to the plates, which were then incu-
Table 1. Primer sequence for polymerase chain reaction

\begin{tabular}{|c|c|}
\hline $\begin{array}{l}\text { Gene } \\
\text { name }\end{array}$ & Sequence \\
\hline IL-1 $\beta$ & $\begin{array}{l}\text { Forward 5'-ATA AGC CCA CTC TAC AGC T-3' } \\
\text { Reverse 5'-ATT GGC CCT GAA AGG AGA GA-3' }\end{array}$ \\
\hline IL-6 & $\begin{array}{l}\text { Forward 5'-AGC GCC TTC GGT CCA GTT GC-3' } \\
\text { Reverse 5'- CCG AAG AGC CCT CAG GCT GGA-3' }\end{array}$ \\
\hline IL-8 & $\begin{array}{l}\text { Forward 5'-TGG GTG CAG AGG GTT GTG-3' } \\
\text { Reverse 5'-CAG ACT AGG GTT GCC AGA TTT A-3' }\end{array}$ \\
\hline HIF- $1 \alpha$ & $\begin{array}{l}\text { Forward 5'-ACA GCA GCC AGA CGA TCA TGC-3' } \\
\text { Reverse 5'-AAA TGA GCT GTC TGT GAT CCA GCA TT }\end{array}$ \\
\hline VEGF & $\begin{array}{l}\text { Forward 5'-TCG GGC CTC CGA AAC CAT G-3' } \\
\text { Reverse 5'-GGT TCC CGA AAC CCT GAG G-3' }\end{array}$ \\
\hline MMP-2 & $\begin{array}{l}\text { Forward 5-'GAG TAA GGG GAT CGC CGT GCA-3' } \\
\text { Reverse 5'-AAG AGG TTG CAA CTC TCC TTG G-3' }\end{array}$ \\
\hline MMP-3 & $\begin{array}{l}\text { Forward 5'-TGC AGA AGT TCC TTG GAT TGG AG-3' } \\
\text { Reverse 5'- GGA GAA TGT GAG TGG AGT CAC C-3' }\end{array}$ \\
\hline MMP-9 & $\begin{array}{l}\text { Forward 5'-GCG GAC ATT GGG AAC CAG CTG TA-3' } \\
\text { Reverse 5'-GAC GCG CCT GTG TAC ACC CAC A-3' }\end{array}$ \\
\hline PDGF & $\begin{array}{l}\text { Forward 5'-AGG AAG CCA TTC CCG CAG TT-3' } \\
\text { Reverse } 5^{\prime} \text {-CTA ACC TCA CCT GGA CCT CT-3' }\end{array}$ \\
\hline bFGF & $\begin{array}{l}\text { Forward 5'- TAT GAA GGA AGA TGG ACG GC-3' } \\
\text { Reverse 5'-AAC AGT ATG GCC TTC TGT CC-3' }\end{array}$ \\
\hline iNOS & $\begin{array}{l}\text { Forward 5'-GGC CTC TCA GCT CAC CCC GA-3' } \\
\text { Reverse 5'-CCA GGC GCA CTG TCT GGT GG-3 }\end{array}$ \\
\hline $\mathrm{COX}-2$ & $\begin{array}{l}\text { Forward 5'-GGT CTG GTG CCT GGT CTG ATG ATG-3' } \\
\text { Reverse 5'-GTC CTT TCA AGG AGA ATG GTG C-3' }\end{array}$ \\
\hline GAPDH & $\begin{array}{l}\text { Forward 5'-AGG TCG GAG TCA ACG GAT TTG G-3' } \\
\text { Reverse 5'-ACA GTC TTC TGG GTG GCA GTG ATG-3' }\end{array}$ \\
\hline CBS & $\begin{array}{l}\text { Forward 5'-TGG ATG CAG GAT CAT TGG GGT G-3' } \\
\text { Reverse 5'-TCC CGG AGG ATC TCG ATG GTG-3' }\end{array}$ \\
\hline CSE & $\begin{array}{l}\text { Forward 5'-AAG AAC CTA AAF CTA TTT ACT CTG-3' } \\
\text { Reverse 5'-TTG GTC CAT TTA ATT ACT CAG GAA-3' }\end{array}$ \\
\hline HO-1 & $\begin{array}{l}\text { Forward 5'-AGA CGG CTT CAA GCT GGT GA-3' } \\
\text { Reverse 5'-TAG GGG ATG ACC TCC TGC CA-3' }\end{array}$ \\
\hline
\end{tabular}

IL, interleukin; HIF, hypoxia inducible factor; VEGF, vascular endothelial growth factor; MMP, matrix metalloproteinase; PDGF, plateletderived growth factor; bFGF, basic fibroblast growth factor; iNOS inducible nitric oxide synthase; COX, cyclooxygenase; GAPDH, Glyceraldehyde 3-phosphate dehydrogenase; CBS, cystathionine $\beta$ synthase; CSE, cystathionine $\gamma$-lyase; HO, heme oxygeanse.

bated for $10 \mathrm{~min}$ at $4^{\circ} \mathrm{C}$. The RiboEX was harvested and placed in a $1.5 \mathrm{~mL}$ tube and gently mixed with $100 \mu \mathrm{L}$ of chloroform. After incubation for $10 \mathrm{~min}$ on ice, samples were centrifuged at $10,000 \times \mathrm{g}$ for $30 \mathrm{~min}$. Supernatants were extracted and mixed with $200 \mu \mathrm{L}$ of isopropanol, and the mixtures were incubated at $4^{\circ} \mathrm{C}$ for $1 \mathrm{~h}$. After centrifuging at 13,000 $\times \mathrm{g}$ for $30 \mathrm{~min}$, pellets were washed with $70 \%(\mathrm{v} / \mathrm{v})$ ethanol. After allowing the ethanol to evaporate completely, the pellets were dissolved in 100 $\mu \mathrm{L}$ of diethylene pyrocarbonate-treated water (Invitrogen Life Technologies). cDNA was prepared using MurineMoloney leukemia virus reverse transcriptase (Promega) according to the manufacturer's instructions. The polymerase chain reaction (PCR) primers used are shown in Table 1. PCR was performed over 30 cycles of: $94^{\circ} \mathrm{C}$ for $20 \mathrm{~s}, 58^{\circ} \mathrm{C}$ for $30 \mathrm{~s}$, and $72^{\circ} \mathrm{C}$ for $45 \mathrm{~s}$. Oligonucleotide primers were purchased from Bioneer (Seoul, Korea). 


\section{In vitro angiogenesis assay}

The in vitro angiogenesis assay was performed using a commercial kit according to the manufacturer's instructions (Millipore, Billerica, MA, USA). Briefly, ECMatrix and diluent buffer were mixed to make a gel, which was then plated in 96-well microplates. HUVECs $\left(1.0 \times 10^{5} /\right.$ $\mathrm{mL}$ ) were seeded in the presence of Korean red ginseng $(0-100 \mu \mathrm{g} / \mathrm{mL})$ and then incubated with sodium hydrogen sulfide at $37^{\circ} \mathrm{C}$ for $4 \mathrm{~h}$. Sprouting tube formation was observed under a light microscope.

\section{Cell proliferation assay}

The cell proliferation assay was performed using a commercial kit according to the manufacturer's instructions (Biological Industries, Kibbutz Beit Haemeck, Israel). Briefly, the MTT reagent and activation reagent were mixed to make a reaction mixture that was added to 96well microplates. HUVECs were incubated at $37^{\circ} \mathrm{C}$ for 2 to $24 \mathrm{~h}$, and absorbance was measured at 450 to $500 \mathrm{~nm}$ with a microplate reader.

\section{Cell migration assay}

HUVECs were cultured in 6-well plates as confluent monolayers at $1 \times 10^{5}$ cells/well. The monolayers were incubated in the absence of serum for $16 \mathrm{~h}$ and wounded by scratching a line across the well with a standard 200 $\mu \mathrm{L}$ pipette tip. The scratched monolayers were then washed twice with serum-free media to remove cell debris and incubated with sodium hydrogen sulfide, PD098959 (MEK1/2 inhibitor, Cell Signaling Technology), or SB209121 (p38 inhibitor, Tocris, UK). The cell-free wound area was recorded at the indicated time points using a charge-coupled device camera connected to an inverted microscope. The remaining cell-free area was calculated as a percentage of the area of the initial scratch.

\section{Statistical analysis}

The data are presented as the mean \pm standard deviation. The statistical significance was assessed using oneway ANOVA. Differences were considered to be significant for values of $p<0.05$.

\section{RESULTS}

Human umbilical vein endothelial cell treatment with sodium hydrogen sulfide increased the expression of cystathionine $\gamma$-lyase as well as inflammatory mediators in vascular endothelial cells

In contrast to previous investigations that targeted gastric epithelial cells to document the anti-inflammatory effects of KRGE [19], in the current study, HUVECs were stimulated with $H$. pylori or the $\mathrm{H}_{2} \mathrm{~S}$ donor $\mathrm{NaHS}$ to investigate the possible mechanisms underlying the cancer preventive effect of KRGE. We were particularly interested in mechanisms related to angiogenesis because the angiogenesis stimulated by $H$. pylori infection can cause either inflammation or carcinogenesis. We hypothesized that one of the key mechanisms of the cancer preventive actions of KRGE against $H$. pylori-associated carcinogenesis might be in ameliorating $H$. pylori-driven angiogenesis. HUVECs stimulated with $100 \mu \mathrm{M}$ NaHS exhibited significantly increased CBS and CSE expression (Fig. 1A). On the basis of data from our previous publication [19] that showed that $H$. pylori infection significantly increased the levels of $\mathrm{H}_{2} \mathrm{~S}$ (as indicated by RTPCR of $\mathrm{H}_{2} \mathrm{~S}$ generating genes and gas chromatography to measure $\mathrm{H}_{2} \mathrm{~S}$ levels in the gastric juices of $\mathrm{H}$. pyloriinfected gastritis patients), we decided that the administration of $100 \mu \mathrm{M}$ NaHS could be used in place of live $H$. pylori bacteria to stimulate $\mathrm{H}_{2} \mathrm{~S}$ generation in HUVECs. The use of NaHS instead of H. pylori infection was preferred under the basis that NaHS has no cytotoxicity at concentrations of up to $300 \mu \mathrm{M}$ (Fig. 1B), whereas 100 multiplicity of infection $\mathrm{H}$. pylori led to significant levels of cytotoxicity (Fig. 1B). As observed in Fig. 1C, treatment with $100 \mu \mathrm{M}$ NaHS significantly increased the expression of interleukin (IL)-8 and inducible nitric oxide synthase (iNOS), to levels comparable to those observed upon $H$. pylori infection. A Western blot for COX-2 showed that NaHS treatment increased the expression of COX-2 at $5 \mathrm{~min}$ and that this increase persisted up to $12 \mathrm{~h}$, whereas iNOS expression was maximized at $10 \mathrm{~min}$ after NaHS treatment and remained higher up to $12 \mathrm{~h}$ than iNOS levels measured before NaHS treatment (Fig. 1D). All of this evidence supports the rationale for stimulating HUVECs with NaHS instead of $H$. pylori infection to evaluate the influence of KRGE on $\mathrm{H}_{2} \mathrm{~S}$ stimulation. Korean red ginseng extracts effectively attenuated
the sodium hydrogen sulfide-stimulated expression
of cystathionine $\gamma$-lyase, inflammatory mediators, and
matrix metalloproteinases in vascular endothelial cells
NaHS treatment significantly increased the expres-
sion of CSE, but KRGE significantly attenuated the
expression of CSE and CBS (Fig. 2A). Similarly, NaHS
significantly increased the expression of inflammatory
mediators including iNOS, COX-2, IL-8, and IL-1b, but
these increases were significantly attenuated by the ad-
ministration of KRGE (Fig. 2B). In addition, NaHS sig- 

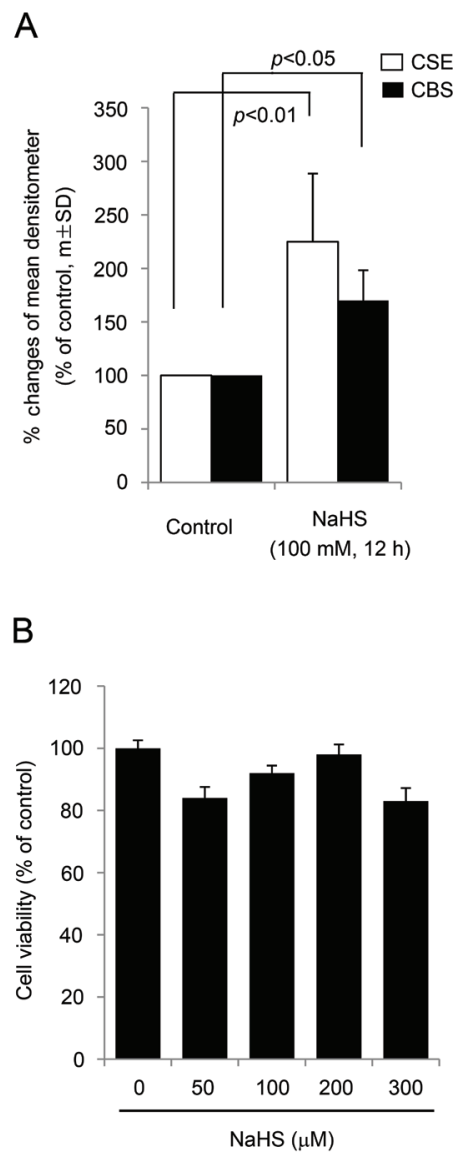

C Helicobacter pylori $(100 \mathrm{MOI}, 12 \mathrm{~h})+\quad-\quad+\quad$ H. pylori $(100 \mathrm{MOI}, 12 \mathrm{~h})-\quad+\quad+$
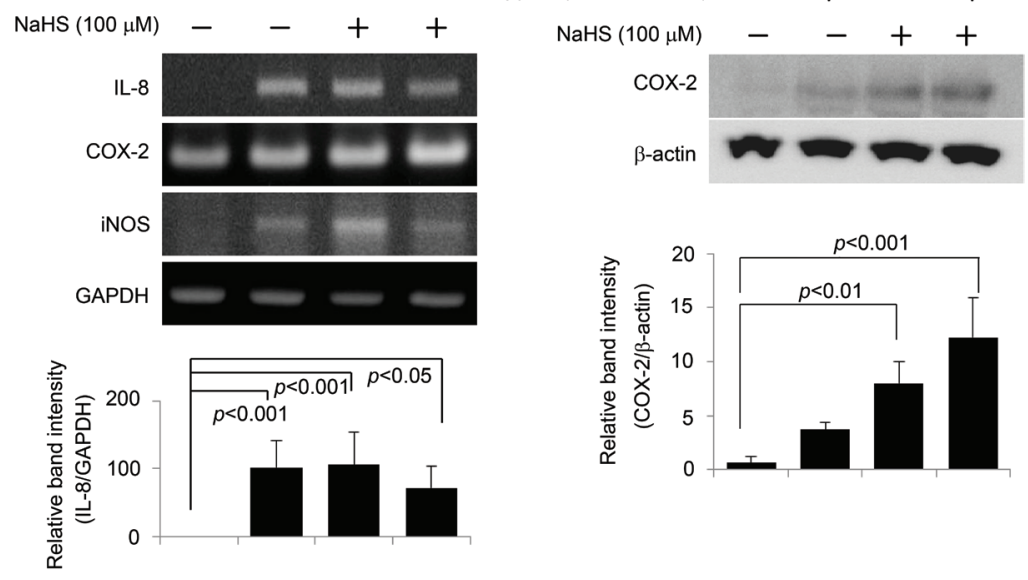

D

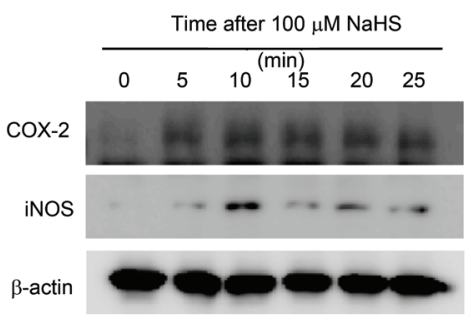

Fig. 1. (A) The expressions of cystathionine $\beta$-synthase (CBS) or cystathionine $\gamma$-lyase (CSE) after sodium hydrogen sulfide (NaHS), agent stimulating $\mathrm{H}_{2} \mathrm{~S}$ generation. NaHS, similar to live Helicobacter pylori challenge [29], increased the expressions of either CBS or CSE. (B) 3-(4, 5-dimethylthiazol-2-yl)-2,5-diphenyltetrazolium bromide assay. The administration of $300 \mathrm{uM}$ NaHS was not cytotoxic to human umbilical vein endothelial cells. (C) Reverse transcription polymerase chain reaction and Western blot. The expressions of cyclooxygenase (COX)-2, interleukin (IL)-8, IL-6, and inducible nitric oxide synthase (iNOS) are induced by $H$. pylori as well as NaHS. Relative band intensity of each mediator showed that $\mathrm{NaHS}$ and $H$. pylori activated the expression of inflammatory mediators. (D) Western blot. Increased expressions of COX-2 were noted from $5 \mathrm{~min}$, whereas expression of iNOS was increased $10 \mathrm{~min}$ after NaSH administration. MOI, multiplicity of infection; GAPDH, Glyceraldehyde 3-phosphate dehydrogenase.

nificantly increased the expression of angiogenic factors including hypoxia inducible factor (HIF)-1a, IL-6, vascular endothelial growth factor (VEGF), platelet-derived growth factor, and MMPs (MMP-2, MMP-3, and MMP9), but these increases were also significantly attenuated by the administration of KRGE (Fig. 2C, D). All of these results suggested that $\mathrm{H}_{2} \mathrm{~S}$ generated by NaHS might be involved in either inflammation or angiogenesis in endothelial cells and that KRGE could ameliorate these changes. Then, because the MAPK and STAT-3 signal transduction pathways are known to be activated in response to $\mathrm{H}_{2} \mathrm{~S}$, we monitored the changes in molecules within these pathways, including STAT3, ERK1/2, and p38, in cells treated with NaHS alone, KRGE alone, or a combination of NaHS and KRGE to confirm that KRGE modulated the signal transduction induced upon $\mathrm{H}_{2} \mathrm{~S}$ challenge. As shown in Fig. 3A, NaHS induced significant activation of STAT3 and ERK, similar to $H$. pylori infection. To further verify ERK pathway activation, an ERK inhibitor was co-challenged with NaHS, as shown in Fig. 3B. The co-administration of KRGE and NaHS attenuated the expression of NaHS-induced COX2 expression to levels similar to those observed upon the addition of an ERK inhibitor. Similarly, KRGE inhibited $\mathrm{H}_{2} \mathrm{~S}$-driven endothelial cell proliferation to levels similar to those produced by a MAPK inhibitor (Fig. 4B). We measured the NaHS-induced activation of both HIF-1a and Akt and found that the influence of KRGE on the inactivation of Akt was statistically significant, whereas its effect on HIF-1a was not significant (Fig. 3C). These results suggest that HIF-1a and Akt might not be critical in the $\mathrm{H}_{2} \mathrm{~S}$-induced angiogenic activation of HUVECs, whereas MMPs are involved. 
A

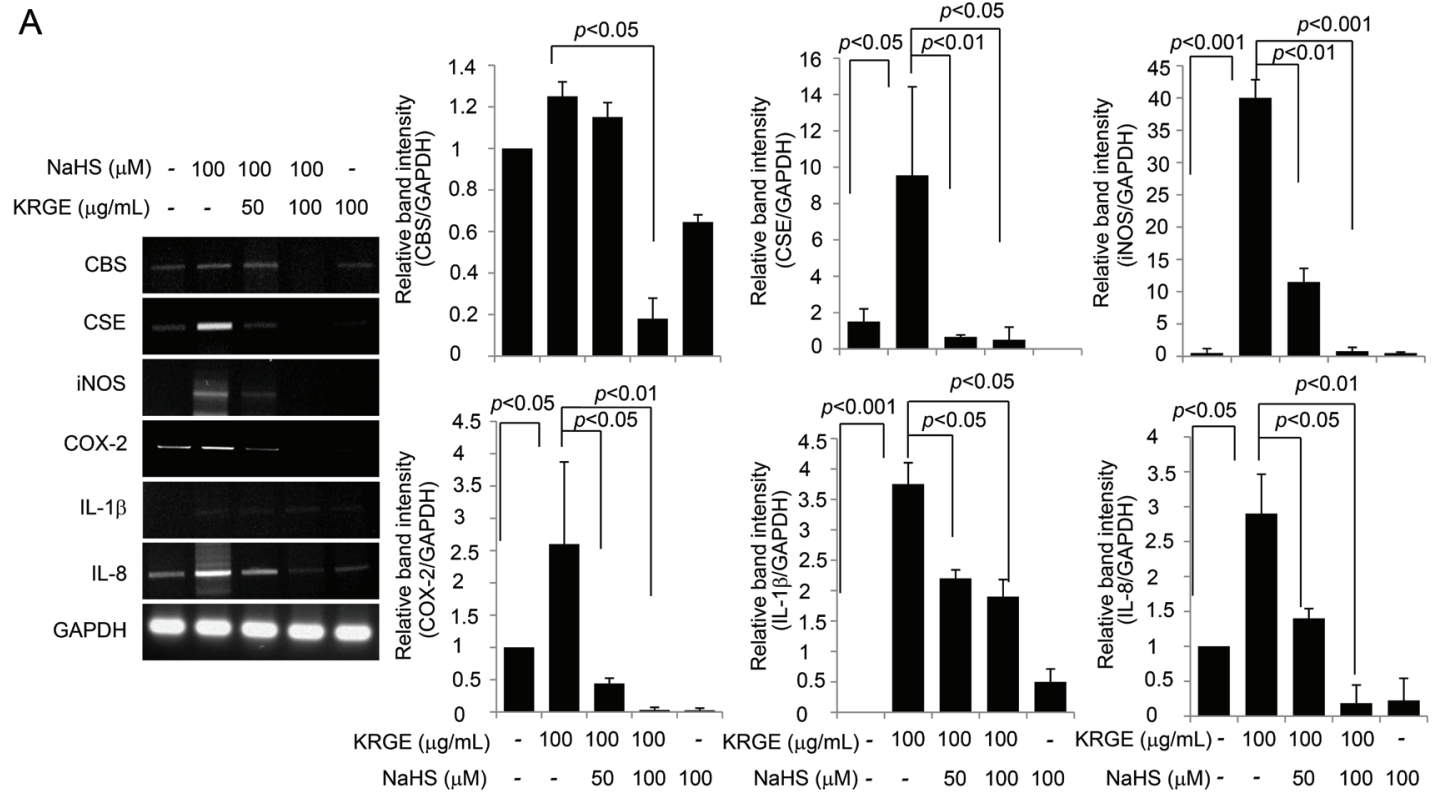

B

NaHS $(\mu \mathrm{M})-100100100 \quad-$ KRGE $(\mu \mathrm{g} / \mathrm{mL})$ - $\quad 50100100$
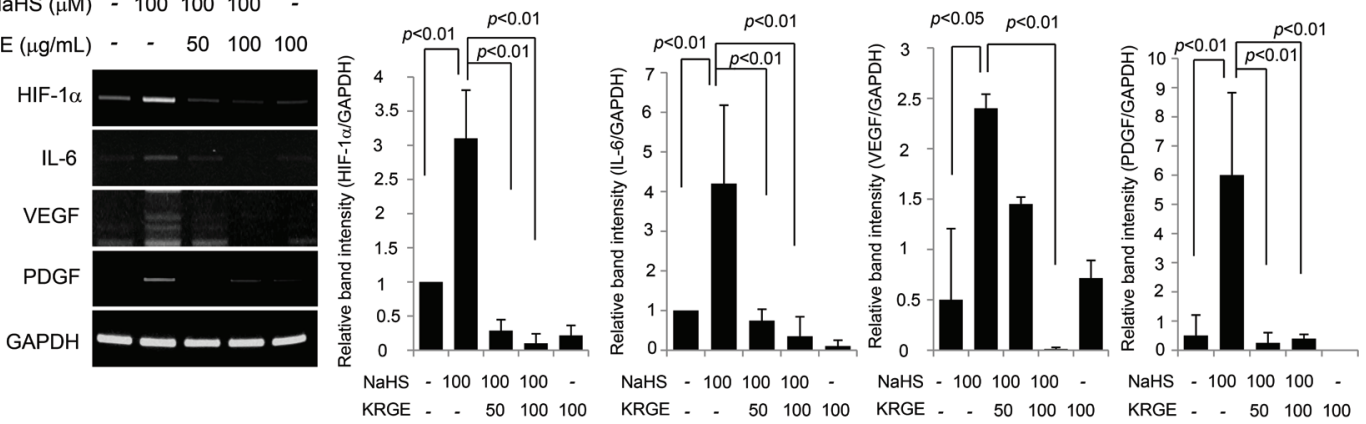

C

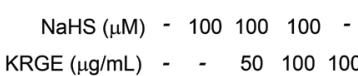
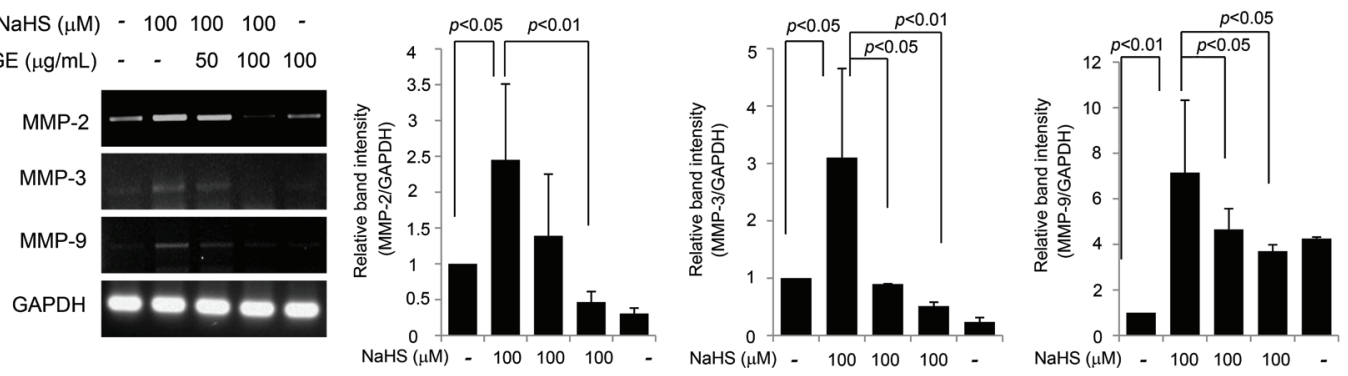

$\operatorname{KRGE}(\mu \mathrm{g} / \mathrm{mL})$ - - $\quad 50 \quad 500100 \mathrm{KRGE}(\mu \mathrm{g} / \mathrm{mL})$ - $\quad$ - $\quad 50 \quad 100100 \mathrm{KRGE}(\mu \mathrm{g} / \mathrm{mL}) \quad$ - $\quad$ - 50100100

Fig. 2. (A) The changes of cystathionine $\beta$-synthase (CBS), cystathionine $\gamma$-lyase (CSE), and inflammatory mediators such as inducible nitric oxide synthase (iNOS), cyclooxygenase (COX)-2, interleukin (IL)-1 $\beta$, and IL-8 after sodium hydrogen sulfide (NaHS) alone or combined with Korean red ginseng extract (KRGE). NaHS significantly increased the expression of CSE. KRGE attenuated the expressions of CSE and CBS. Relative band intensity shows that Korean red ginseng has meaningful effect on attenuating the expression of CSE and CBS. The expressions of iNOS, COX-2, IL-8, and IL-6 were all increased with $100 \mu \mathrm{M} \mathrm{NaHS}$, while KRGE significantly decreased these expressions of NaHS-induced inflammatory mediators. Relative band intensity showed that KRGE has meaningful effect on attenuating the expression of NaHS inducing inflammatory mediators. (B) The changes of angiogenic factors including hypoxia inducible factor (HIF)-1 $\alpha$, IL-6, vascular endothelial growth factor (VEGF), and platelet-derived growth factor (PDGF). $100 \mu \mathrm{M}$ NaHS increased these angiogenic factors significantly, while KRGE significantly decreased these expressions of NaHS-induced angiogenic factors. (C) Reverse transcription polymerase chain reaction for matrix metalloproteinases (MMPs). NaHS significantly increased the expressions of MMP-2, MMP-3, and MMP-9, while KRGE could attenuate these expressions of $\mathrm{H}_{2} \mathrm{~S}-\mathrm{driven}$ MMPs. GAPDH, Glyceraldehyde 3-phosphate dehydrogenase. 
A
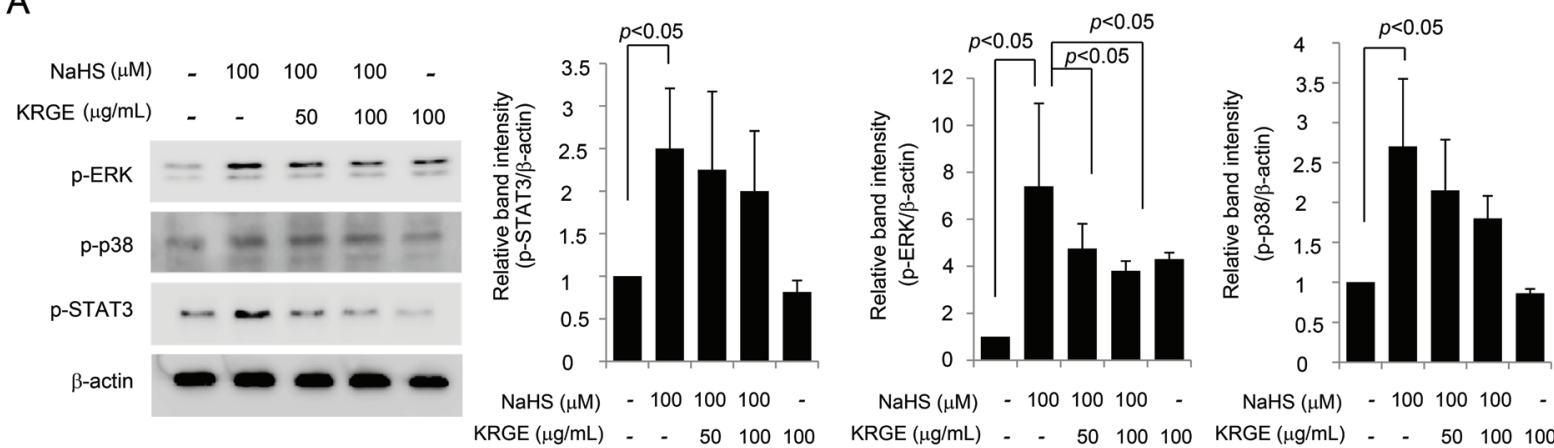

$\mathrm{NaHS}(\mu \mathrm{M}) \quad-100100100$ KRGE $(\mu \mathrm{g} / \mathrm{mL}) \quad$ - $\quad-50100100$ KRGE $(\mu \mathrm{g} / \mathrm{mL}) \quad$ - $\quad 50100100 \mathrm{KRGE}(\mu \mathrm{g} / \mathrm{mL}) \quad$ - 50100100

B

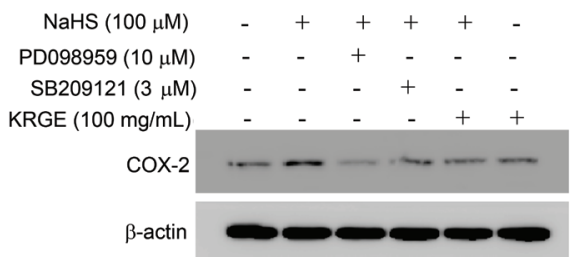

C
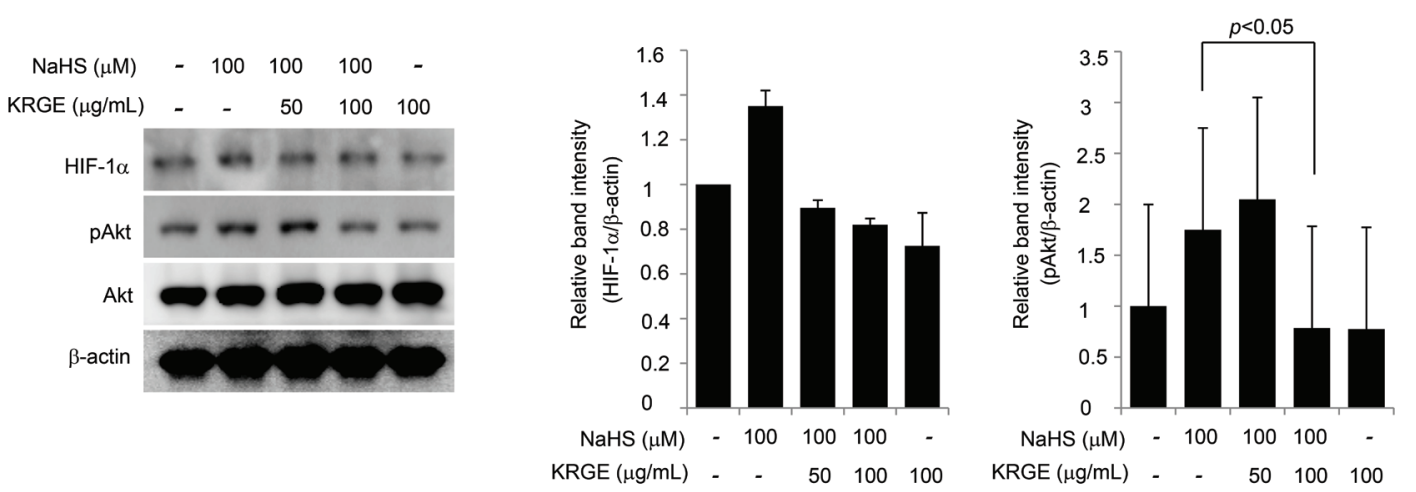

Fig. 3. (A) Western blotting for several activated levels of STAT3, ERK1/2, and p38. Sodium hydrogen sulfide (NaHS) significantly activated STAT3, ERK1/2, and p38, but Korean red ginseng extract (KRGE) was efficiently inactivated these signals. Relative band intensity showed that KGRE has meaningful inactivating effect on ERK1/2, though inhibitory effects on STAT3 and p38. (B,D) Western blot for cyclooxygenase (COX)2 according to group. The increased expressions of COX-2, also implicated as angiogenic factor after NaHS, were significantly decreased with ERK inhibitor, p38 inhibitor, and KRGE. (C) The change of HIF-1 $\alpha$ and Akt. Akt and hypoxia inducible factor (HIF)-1 $\alpha$ were both engaged in inflammation or angiogenesis. NaHS increased these expressions of HIF-1 $\alpha$ and activated Akt, but not to the level of statistical significance. GAPDH,Glyceraldehyde 3-phosphate dehydrogenase.

\section{Korean red ginseng extract directly decreased hy- drogen sulfide-associated angiogenesis}

We found that NaHS treatment led to an increased inflammatory response as well as the expression of angiogenic factors in endothelial cells, indicating that $\mathrm{H}_{2} \mathrm{~S}$ might intervene in increased angiogenesis related to inflammation activation. Because angiogenesis and inflammation are key molecular mechanisms related to H. pylori-associated carcinogenesis, we hypothesized that agents controlling $H$. pylori-associated angiogenesis could be potential cancer preventive agents. Therefore, to test the hypothesis that Korean red ginseng might efficiently decrease NaHS-induced angiogenesis, an in vitro angiogenesis assay was performed (Fig. 4A). NaHS significantly increased endothelial cell tube formation, but Korean red ginseng decreased these $\mathrm{H}_{2} \mathrm{~S}$-driven angiogenic activities. Because angiogenesis is associated with the increased proliferation of endothelial cells, we also measured proliferative activities according to group (Fig. 4B). As observed in Fig. 4B, PD098959, a MEK1/2 inhibitor that acts upstream of ERK, and the p38 inhibitor SB209121 both significantly blocked NaHSinduced endothelial proliferation. In a similar fashion, the increase in endothelial cell proliferation after NaHS was significantly abrogated by different doses of KRGE $(p<0.001)$, signifying that the anti-angiogenic activities 
A

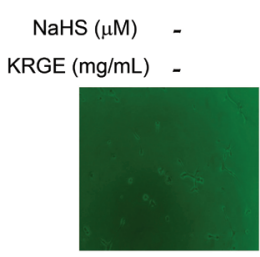

100

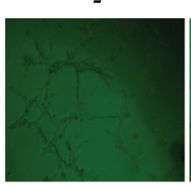

100

50

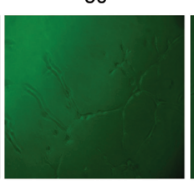

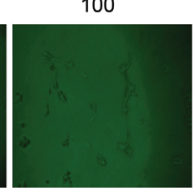

100

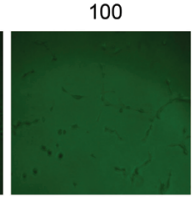

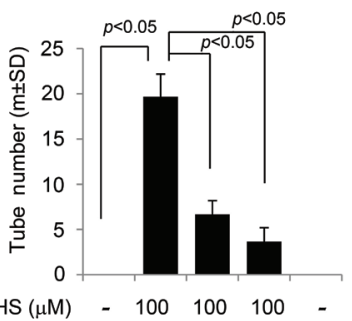

RGE $(\mathrm{mg} / \mathrm{mL}) \quad-\quad 50 \quad 100100$

B

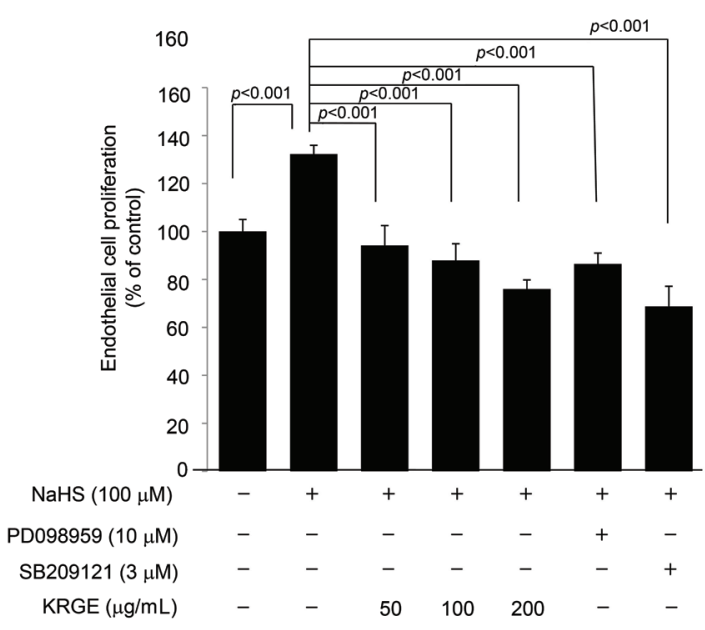

C
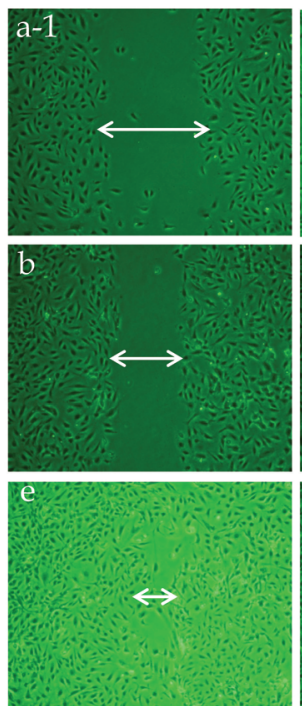
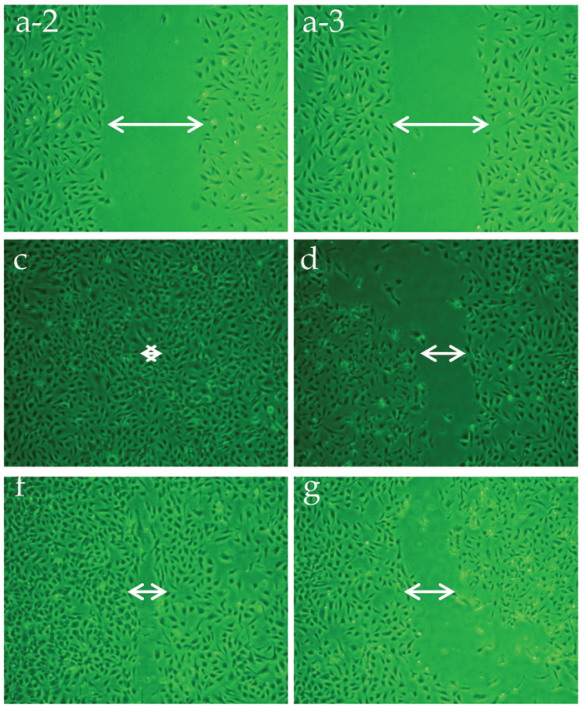

Fig. 4. (A) In vitro angiogenesis assay. $100 \mu \mathrm{M}$ sodium hydrogen sulfide (NaHS) administration resulted in increased capillary tube formations Korean red ginseng extract (KRGE) alone did not affect tube formation, but co-treatment of NaHS and KRGE significantly decreased endothelial tube formations. (B) Endothelial cell proliferation assay. NaHS significantly increased proliferation of endothelial cells, but the co-treatment with MEK inhibitor (upstream kinase of ERK, PD098959) or p38 inhibitor (SB209121) resulted in significant decreases in NaHS-driven endothelial cell proliferation. KRGE also led to significant reduction in NaHS-driven endothelial cell proliferation. (C) In vitro wound assay. NaHS significantly accelerated wound closure, but MAPK inhibitor as well as KRGE delayed wound closure, suggesting KRGE contributed to decreasing endothelial cell migration as much as SB209121 and PD098959. (a-1, a-2, a-3) controls at start time point, (b) no treatment group, (c) $100 \mu \mathrm{M}$ NaHS administration, (d) PD098959 in the presence of $100 \mu \mathrm{M} \mathrm{NaHS,} \mathrm{(e)} \mathrm{SB209121} \mathrm{in} \mathrm{the} \mathrm{presence} \mathrm{of} 100 \mu \mathrm{M} \mathrm{NaHS}$, (f) $100 \mu \mathrm{g} / \mathrm{mL} \mathrm{KRGE}$ in the presence of $100 \mu \mathrm{M} \mathrm{NaHS}$, (g) $100 \mu \mathrm{g} / \mathrm{mL}$ KRGE alone without NaHS. Arrow directs the width of wound and asterisk in figure $\mathrm{c}$ shows the absence of wound, complete closure. \% decrement in wound size according to treatment group was presented as mean \pm SD. 
of Korean red ginseng on $\mathrm{H}_{2} \mathrm{~S}$-driven angiogenesis might be mediated by the inhibition of $\mathrm{H}_{2} \mathrm{~S}$-driven HUVEC proliferation. These results were further validated with an in vitro wound healing assay using cultured HUVECs (Fig. 4C). Compared with the control group, NaHS accelerated wound closure (c shows a representational wound with NaHS), whereas cotreatment with an ERK inhibitor (d, PD098959) or p38 inhibitor (e, SB209121) retarded wound closure even in the context of $\mathrm{NaHS}$ administration. KRGE alone or KRGE in the presence of NaHS also retarded wound closure (Fig. 4C), and the mean wound sizes of are shown in Fig. 4C. All these results showed that NaHS-generated $\mathrm{H}_{2} \mathrm{~S}$ contributed to the significant acceleration of endothelial cell proliferation, whereas KRGE significantly inhibited $\mathrm{H}_{2} \mathrm{~S}$-driven endothelial cell proliferation.

\section{DISCUSSION}

The continuous modulation of angiogenesis is considered to be an important therapeutic strategy for human health, especially in $H$. pylori-associated inflammation propagation or carcinogenesis [20,21]. As results, numerous bioactive plant compounds have been tested for antiangiogenic potential; the most frequently studied and reportedly effective of these compounds include Korean red ginseng and polyphenols present in fruits and vegetables [22]. In the current study, we show for the first time that KRGE exerts strong anti-angiogenic effects against $H$. pylori-associated $\mathrm{H}_{2} \mathrm{~S}$ generation through the regulation of multiple molecular targets, including angiogenic growth factors like VEGF, ILs, HIF-1a, MMPs, transcription factors, and signaling molecules including NF-kB, PI3K/Akt, ERK1/2 and p38.

In a study of the signal transduction pathways implicated in $\mathrm{H}_{2} \mathrm{~S}$-induced angiogenesis, Papapetropoulos et al. [23] incubated endothelial cells (EC) with $\mathrm{H}_{2} \mathrm{~S}$ and observed the increased phosphorylation of Akt, ERK, and p38. Similarly, our results showed that the p38 inhibitor SB203580 significantly abolished $\mathrm{H}_{2} \mathrm{~S}$-induced EC motility, as shown in Fig. 4. The pharmacological inhibition of $\mathrm{H}_{2} \mathrm{~S}$ production or CSE silencing attenuated VEGF signaling and EC migration, suggesting that endothelial $\mathrm{H}_{2} \mathrm{~S}$ synthesis leads to the pro-angiogenic action of VEGF. In vascular tissues, $\mathrm{H}_{2} \mathrm{~S}$ is mainly produced from L-cysteine by CSE rather than CBS, and $\mathrm{H}_{2} \mathrm{~S}$ stimulated cell proliferation, migration and tube formation. Therefore, $\mathrm{H}_{2} \mathrm{~S}$ is a double-edged sword, with positive or negative functions depending on the context of the disease. For instance, Szabo and Papapetropoulos [24] demonstrated the positive role of endogenous $\mathrm{H}_{2} \mathrm{~S}$ in the angiogenic response to wounding and concluded that the topical administration of $\mathrm{H}_{2} \mathrm{~S}$ promotes wound healing, whereas the genetic ablation of CSE attenuates wound healing, suggesting that the pharmacological modulation of $\mathrm{H}_{2} \mathrm{~S}$-mediated angiogenic pathways may open the door for novel therapeutic approaches. However, because angiogenesis is a key process in the promotion of cancer, especially $H$. pylori-associated gastric carcinogenesis, the inhibition of angiogenesis has been proposed as a general strategy to fight $H$. pylori-associated gastritis and other cancers.

Chronic infection with the gastric pathogen $H$. pylori significantly increases the risk of developing atrophic gastritis, peptic ulcer disease, and gastric adenocarcinoma due to the activation of angiogenesis. Keates et al. [25] studied the molecular mechanisms through which H. pylori up-regulated the expression of plasminogen activator inhibitor (PAI)-1, a member of the urokinase activator system that is involved in tumor metastasis and angiogenesis, and found that the up-regulation of PAI1 and the resulting angiogenesis in $H$. pylori-infected gastric epithelial cells may contribute to carcinogenesis. Although VEGF is an important modulator of gastric mucosal repair, VEGF is also overexpressed in gastric cancer. For example, Tuccillo et al. [21] evaluated the expression of VEGF in the gastric mucosa of H. pyloriinfected and $H$. pylori-non-infected dyspeptic patients as well as in gastric cancer tissues. An increase in VEGF expression was associated with a significant increase in neo-angiogenesis, as assessed by the presence of CD34positive micro-vessels. $H$. pylori gastritis is associated with an up-regulation of VEGF expression, which parallels the increased formation of blood vessels in the gastric mucosa, suggesting that increased VEGF expression and neo-angiogenesis may contribute to $H$. pylori-related gastric carcinogenesis and gastritis. However, angiogenesis is also a double-edged sword in $H$. pylori infection because although $H$. pylori-associated angiogenesis promotes carcinogenesis, defective angiogenesis is associated with delayed ulcer healing or high ulcer recurrence in H. pylori infection [26]. Therefore, we infer that balanced angiogenic activities might be essential in disease prevention, and a more detailed strategy to modulate the mechanistic implication of gastrin, COX-2, several types of growth factor, $\mathrm{NO} / \mathrm{NO}$ synthase, E-cadherin/b-catenin systems, and apoptosis as well as angiogenesis will be required to prevent $H$. pylori-induced gastric carcinogenesis.

In our search for strategies to prevent $H$. pylori-asso- 
ciated carcinogenesis, we evaluated non-microbial approaches rather than simple eradication because the inactivation of carcinogenic pathways seems to be an equally or more efficient strategy than the simple removal of the bacteria. The chronic administration of KRGE may be one such wise strategy, as indicated by our previous publications that showed the efficacy of Korean red ginseng in reducing $H$. pylori-associated gastric inflammation, lowering oxidative stress, reducing cytotoxicity, and decreasing mutagenesis. Among the key players engaged in the connection between $H$. pylori infection and gastric carcinogenesis, we focused on $\mathrm{H}_{2} \mathrm{~S}$-driven inflammation and angiogenesis and found for the first time that KRGE could efficiently regulate these events. Previously, KRGE was reported to relieve halitosis by suppressing $\mathrm{H}$. pyloriassociated $\mathrm{H}_{2} \mathrm{~S}$ generation and to improve erosive and ulcerative lesions [27-29]; the current study identified another suppressive effect of KRGE against $\mathrm{H}_{2} \mathrm{~S}$-driven angiogenesis.

Though angiogenesis is notorious for its role in promoting carcinogenesis, angiogenesis is important for cardiovascular protection, wound healing, and tissue regeneration. Kim et al. [30] investigated the effects of an aqueous Korean red ginseng extract on angiogenesis and its underlying signaling mechanisms and showed that KRGE increased in vitro proliferation, migration, and tube formation in HUVECs as well as in vivo angiogenesis without increasing VEGF expression. This finding is somewhat inconsistent with our results showing that Korean red ginseng attenuated $\mathrm{H}_{2} \mathrm{~S}$-triggered angiogenesis; this discrepancy may indicate that KRGE exerts its biological actions differently according to the stimulator used, the cell context, and the underlying pathological conditions. KRGE activity might also be dependent on physiological context, i.e., promoting angiogenesis in ischemic heart disease or to promote wound healing in other benign conditions but blocking angiogenesis in pathologic conditions like inflammatory disorders, obesity, asthma, diabetes, cirrhosis, multiple sclerosis, endometriosis, AIDS, bacterial infections, and autoimmune disease as well as tumorigenesis, invasion, and metastasis. One interesting finding is that, irrespective of angiogenesis inhibition or activation with KRGE, the underlying molecular mechanisms regulating angiogenesis were similar, involving the phosphorylation of ERK1/2, Akt, endothelial nitric oxide synthase (eNOS), and other angiogenic factors downstream of KRGE. The inhibition of PI3K activity by wortmannin completely inhibited KRGE-induced angiogenesis, indicating that the phosphorylation of Akt and ERK1/2 and subsequent eNOS and PI3K/Akt activation is an upstream event in the KRGE-mediated angiogenic or anti-angiogenic pathway.

Recent studies have shown that several natural compounds inhibit angiogenesis, and numerous bioactive plant compounds have been tested for their antiangiogenic potential, including the polyphenols resveratrol, curcumin, and $P$. ginseng as well as miscellaneous compounds from garlic, Hypericum perforatum, Coptis chinensis and Rheum palmatum [31-33]. Among these compounds, Korean red ginseng, resveratrol (a polyphenol present in red wine and grapeseed), epigallocatechin3-gallate from green tea, and curcumin from Curcuma longa have been investigated extensively. Given its value and current levels of documentation, Korean red ginseng should be studied in a large-scale, long-term clinical trial to determine its efficacy as a potential cancer preventive agent in the context of $H$. pylori infection. In conclusion, $H$. pylori infection-associated $\mathrm{H}_{2} \mathrm{~S}$ might induce gastric inflammation, cause halitosis, damage the gastric mucosa, and contribute to carcinogenesis through the promotion of angiogenesis. KRGE efficiently blocked H. pylori-associated $\mathrm{H}_{2} \mathrm{~S}$ generation, and these activities may mitigate $H$. pylori-associated inflammation as well as carcinogenesis.

\section{ACKNOWLEDGEMENTS}

The current study was supported by the 2010 grant from the Korean Society of Ginseng funded by Korea Ginseng Corporation.

\section{REFERENCES}

1. Kashiba M, Kajimura M, Goda N, Suematsu M. From $\mathrm{O}_{2}$ to $\mathrm{H}_{2} \mathrm{~S}$ : a landscape view of gas biology. Keio J Med 2002;51:1-10.

2. Wang R. Two's company, three's a crowd: can $\mathrm{H}_{2} \mathrm{~S}$ be the third endogenous gaseous transmitter? FASEB J 2002;16:1792-1798.

3. Abe K, Kimura H. The possible role of hydrogen sulfide as an endogenous neuromodulator. J Neurosci 1996;16:1066-1071.

4. Fiorucci S, Distrutti E, Cirino G, Wallace JL. The emerging roles of hydrogen sulfide in the gastrointestinal tract and liver. Gastroenterology 2006;131:259-271.

5. Mancardi D, Penna C, Merlino A, Del Soldato P, Wink DA, Pagliaro P. Physiological and pharmacological features of the novel gasotransmitter: hydrogen sulfide. Biochim Biophys Acta 2009;1787:864-872.

6. Kasparek MS, Linden DR, Kreis ME, Sarr MG. 
Gasotransmitters in the gastrointestinal tract. Surgery 2008; 143:455-459.

7. Szabo C. Hydrogen sulphide and its therapeutic potential. Nat Rev Drug Discov 2007;6:917-935.

8. Moore PK, Bhatia M, Moochhala S. Hydrogen sulfide: from the smell of the past to the mediator of the future? Trends Pharmacol Sci 2003;24:609-611.

9. Wallace JL. Hydrogen sulfide-releasing anti-inflammatory drugs. Trends Pharmacol Sci 2007;28:501-505.

10. Nakao A, Sugimoto R, Billiar TR, McCurry KR. Therapeutic antioxidant medical gas. J Clin Biochem Nutr 2009;44:1-13.

11. Zanardo RC, Brancaleone V, Distrutti E, Fiorucci S, Cirino G, Wallace JL. Hydrogen sulfide is an endogenous modulator of leukocyte-mediated inflammation. FASEB J 2006;20:2118-2120.

12. Li L, Bhatia M, Zhu YZ, Zhu YC, Ramnath RD, Wang ZJ, Anuar FB, Whiteman M, Salto-Tellez M, Moore PK. Hydrogen sulfide is a novel mediator of lipopolysaccharide-induced inflammation in the mouse. FASEB J 2005;19:1196-1198.

13. Zhang H, Zhi L, Moochhala SM, Moore PK, Bhatia M. Endogenous hydrogen sulfide regulates leukocyte trafficking in cecal ligation and puncture-induced sepsis. J Leukoc Biol 2007;82:894-905.

14. Yang G, Yang W, Wu L, Wang $\mathrm{R}$. $\mathrm{H}_{2} \mathrm{~S}$, endoplasmic reticulum stress, and apoptosis of insulin-secreting beta cells. J Biol Chem 2007;282:16567-16576.

15. Bhatia M, Wong FL, Fu D, Lau HY, Moochhala SM, Moore PK. Role of hydrogen sulfide in acute pancreatitis and associated lung injury. FASEB J 2005;19:623-625.

16. Yun TK. Panax ginseng: a non-organ-specific cancer preventive? Lancet Oncol 2001;2:49-55.

17. Kim DK, Lee JA, Kim YB, Lee KM, Hahm KB. A randomized controlled trial assessing Korean red ginseng treatment of Helicobacter pylori-associated chronic gastritis. Korean J Intern Med 2007;72:20-28.

18. Lee SY, Shin YW, Hahm KB. Phytoceuticals: mighty but ignored weapons against Helicobacter pylori infection. J Dig Dis 2008;9:129-139.

19. Lee JS, Kwon KA, Jung HS, Kim JH, Hahm KB. Korea red ginseng on Helicobacter pylori-induced halitosis: newer therapeutic strategy and a plausible mechanism. Digestion 2009;80:192-199.

20. Konturek PC, Konturek SJ, Brzozowski T. Helicobacter pylori infection in gastric cancerogenesis. J Physiol Pharmacol 2009;60:3-21.

21. Tuccillo C, Cuomo A, Rocco A, Martinelli E, Staibano S, Mascolo M, Gravina AG, Nardone G, Ricci V, Ciardiello F et al. Vascular endothelial growth factor and neo- angiogenesis in $H$. pylori gastritis in humans. J Pathol 2005;207:277-284.

22. Mojzis J, Varinska L, Mojzisova G, Kostova I, Mirossay L. Antiangiogenic effects of flavonoids and chalcones. Pharmacol Res 2008;57:259-265.

23. Papapetropoulos A, Pyriochou A, Altaany Z, Yang G, Marazioti A, Zhou Z, Jeschke MG, Branski LK, Herndon $\mathrm{DN}$, Wang $\mathrm{R}$ et al. Hydrogen sulfide is an endogenous stimulator of angiogenesis. Proc Natl Acad Sci U S A 2009;106:21972-21977.

24. Szabo C, Papapetropoulos A. Hydrogen sulphide and angiogenesis: mechanisms and applications. Br J Pharmacol 2011;164:853-865.

25. Keates AC, Tummala S, Peek RM Jr, Csizmadia E, Kunzli B, Becker K, Correa P, Romero-Gallo J, Piazuelo MB, Sheth $\mathrm{S}$ et al. Helicobacter pylori infection stimulates plasminogen activator inhibitor 1 production by gastric epithelial cells. Infect Immun 2008;76:3992-3999.

26. Gunawan E, Tsuji S, Tsujii M, Kimura A, Sun WH, Sawaoka H, Sasayama Y, Sasaki Y, Kawano S, Hori M. Influences of Helicobacter pylori on gastric angiogenesis and ulcer healing in mice. J Gastroenterol Hepatol 2002;17:960-965.

27. Lee SJ, Park JY, Choi KS, Ock CY, Hong KS, Kim YJ, Chung JW, Hahm KB. Efficacy of Korean red ginseng supplementation on eradication rate and gastric volatile sulfur compound levels after Helicobacter pylori eradication therapy. J Ginseng Res 2010;34:122-131.

28. Park S, Yeo M, Jin JH, Lee KM, Jung JY, Choue R, Cho SW, Hahm KB. Rescue of Helicobacter pylori-induced cytotoxicity by red ginseng. Dig Dis Sci 2005;50:12181227.

29. Park S, Yeo M, Jin JH, Lee KM, Kim SS, Choi SY, Hahm KB. Inhibitory activities and attenuated expressions of 5-LOX with red ginseng in Helicobacter pylori-infected gastric epithelial cells. Dig Dis Sci 2007;52:973-982.

30. Kim YM, Namkoong S, Yun YG, Hong HD, Lee YC, Ha KS, Lee H, Kwon HJ, Kwon YG, Kim YM. Water extract of Korean red ginseng stimulates angiogenesis by activating the PI3K/Akt-dependent ERK1/2 and eNOS pathways in human umbilical vein endothelial cells. Biol Pharm Bull 2007;30:1674-1679.

31. Yance DR Jr, Sagar SM. Targeting angiogenesis with integrative cancer therapies. Integr Cancer Ther 2006;5:9-29.

32. Sagar SM, Yance D, Wong RK. Natural health products that inhibit angiogenesis: a potential source for investigational new agents to treat cancer. Part 2. Curr Oncol 2006;13:99-107.

33. Dulak J. Nutraceuticals as anti-angiogenic agents: hopes and reality. J Physiol Pharmacol 2005;56 Suppl 1:51-67. 